\title{
Self-Evaluations and Social Comparison
}

\begin{abstract}
Zhuoyuan Song
Beijing Haidian Kaiwen academy, Beijing 100195, China.

Email: frank13718663145@gmail.com

ABSTRACT

This study will be focuse on the effect of social comparison on implicit self-esteem and self-evaluation. The study is about how unconscious process may be affected by social comparison. The study is based on hypothetical study data and Meta-analysis. By comparing the result from different groups of participants, I tried to find is the role model and or individuals who people look up to influencing how people evaluate themselves, is people started to idealize themselves? Or there is not effect on the evaluation. The significance of the experiment is to see whether self-esteem and selfevaluation can be influenced by the social comparison.
\end{abstract}

Keywords: Self-evaluation, implicit self-esteem, ideal self, social comparison

\section{INTRODUCTION}

\subsection{Implicit Self-esteem and self-evaluation}

When people were evaluating themselves, selfesteem was always involved. Self-esteem refers to an individual's overall positive evaluation of themselves (Gecas 1982; Morris 1990). [1,2]. It is composed of two distinct dimensions, competence dimension and worth dimension. (Gecas 1982; Gecas \& Schwalbe 1983). [1,3]. The competence dimension is the phenomenon that people see themselves as capable and effective toward problems. The worth refers to the phenomenon that individuals feel they are valued as a useful person. Within Self-esteem, there is a part called implicit self-esteem, which is a person's disposition to evaluate themselves in a spontaneous, automatic, or unconscious way. However, is there a clear correlation between social comparison and implicit self-esteem? Does social comparison lead people to a more positive self-evaluation?

What are people doing when they are evaluating themselves? Some psychologists believed that selfevaluation is a process through conscious self-reflection (Sedikides \& Strube 1997) [4]. They asked themselves questions as they self-attribute all their behaviors.

In the majority of implicit self-esteem measures, people tend to rate themselves in a highly positive way. The overestimation of one's personality traits and own abilities are stated to be a sign of positive affect from the self to objects associated with the self (Farham, Wald \& Banaji 1999) [5]. This mental sign is automatic and unconscious. Implicit self-esteem therefore can be seen as a positivity bias for things related to the self.

We can highlight some preliminary studies of implicit self-esteem impacts based on the preceding accounts. When people come across stimuli that are correlated with themselves in some ways, a branch of their selfevaluations may be automatically triggered (Bargh, Chaiken, Raymond \& Hymes 1996; Fazio, Sanbonmatsu, Powell \& Kardes 1996) [6,7]. Because of their irrational nature, these evaluations are frequently broad and illdefined, making them easily mistaken comparing to other evaluations of other stimuli based (Murphy \& Zajonc 1993) [8]. Furthermore, because people's instinctive selfevaluation is usually positive (Paulhus 1993) [9], activating automatic self-evaluations will frequently make positive evaluations more accessible in memory. As a result, people's judgments of self-associated stimuli may be frequently be positive based on the memory.

Along with our adolescence and progress, we formed self-evaluations. Initially, humans' self-evaluations leaned toward positive feedback, and this propensity for positivity can indicate a process of self-improvement (Solomon, Greenberg \& Pyszczynski) [10]. Selfevaluation skills did not appear until early adolescence, which is when children truly begin to develop them.

\subsection{Ideal Self and social comparison}

The ideal self is a psychological part of the entire self (Baumeister 2010) [11]. The ideal self is kind of like a link toward self-regulation. It helps us to organize our drives for improvements and direct it toward the right 
way. The deep affect creates a cognitive pattern for people's behavior and thoughts, the ideal self-acts like a visualization of our craved future achievements and accomplishments. The ideal self can become a motivational core and the generator for positive emotion (Boyatzis \& Akrivou 2006) [12]. Occasionally, people choose an already exist individual to be a substantialized representation of their ideal self. Human beings have got an intrinsic desire to compare with others, goals such as evaluating themselves (Festinger 1954) [13], and stay well-being (Kleinke \& Miller) [14]. Usually the substantialized representation individuals choose will be containing characteristics superior than others (Wood 1989) [15]. Especially under nowadays' situation, where people have easy access to social media, people are constantly comparing themselves with others on social media platforms. Social media are showing idealized and positive images to users (Chou \& Edge 2012) [16]. In life, we can find a common phenomenon, which is people tend to sometimes write their personal file more positively and even exaggerate it under some circumstances. People might be comparing their realistic offline selves to the idealized others, which will sometimes blur their selfevaluation. People strive to be their ideal self, and sometimes they'll assimilate toward their ideal self. Within this study, the goal is to see whether people automatically or unintentionally evaluate themselves similar to their real life ideal self-representations. Additionally, people do not compare themselves to everyone they see on social media or on the street. They do so because they consider it as useful, they examine their intentional comparison from multiple aspects, and then they determine whether the comparison is useful or not (Jones \& Gerard 1967) [17].

\subsection{Aim}

The goal of this article is to test the relationship between people's ideal self and their self-evaluation, that if when people were set in to a specific condition and compare their result with the unconditioned group. For example, hypothetically one argued that social comparison can totally affect an individual's selfevaluation. One can use tests to assess an individual's self-evaluation and they compare the data with their evaluation of their role model. If simply comparing the result is not effective and conclusive, the analysis of trend will be used. Trend analysis will look at the overall trend with both of the two groups, to see whether is there one group who evaluate themselves better base on the trend.

\section{METHOD}

\subsection{Survey design}

The survey contains fifteen questions. All the questions in the survey will required people to choose rate number from the range 1 to 5 ( 1 representing completely disagree, and 5 representing completely disagree). Participants were first asked to give an overall score on their own attractiveness and personality. After that, there were questions asking basically about how people will do under specific circumstances. Participants were asked to choose the rate number based on their own view of things. The questions were very specific and detailed. The survey questions for the participant's role model and the participant themselves were the same. When participants were trying to evaluate their role model, they were asked to evaluate them through their own knowledge about them. Participants will be answering all the questions from their role model's perspective. When they encounter questions, they don't know how to answer, they were required to give a considerable answer base on their knowledge about their role model. Participants not having enough knowledge toward their role model wasn't a big problem, because as mentioned in the social comparison paragraph, the role model is just a substantially representation of people's ideal self. They could give rate numbers based on their knowledge of their own ideal self. 


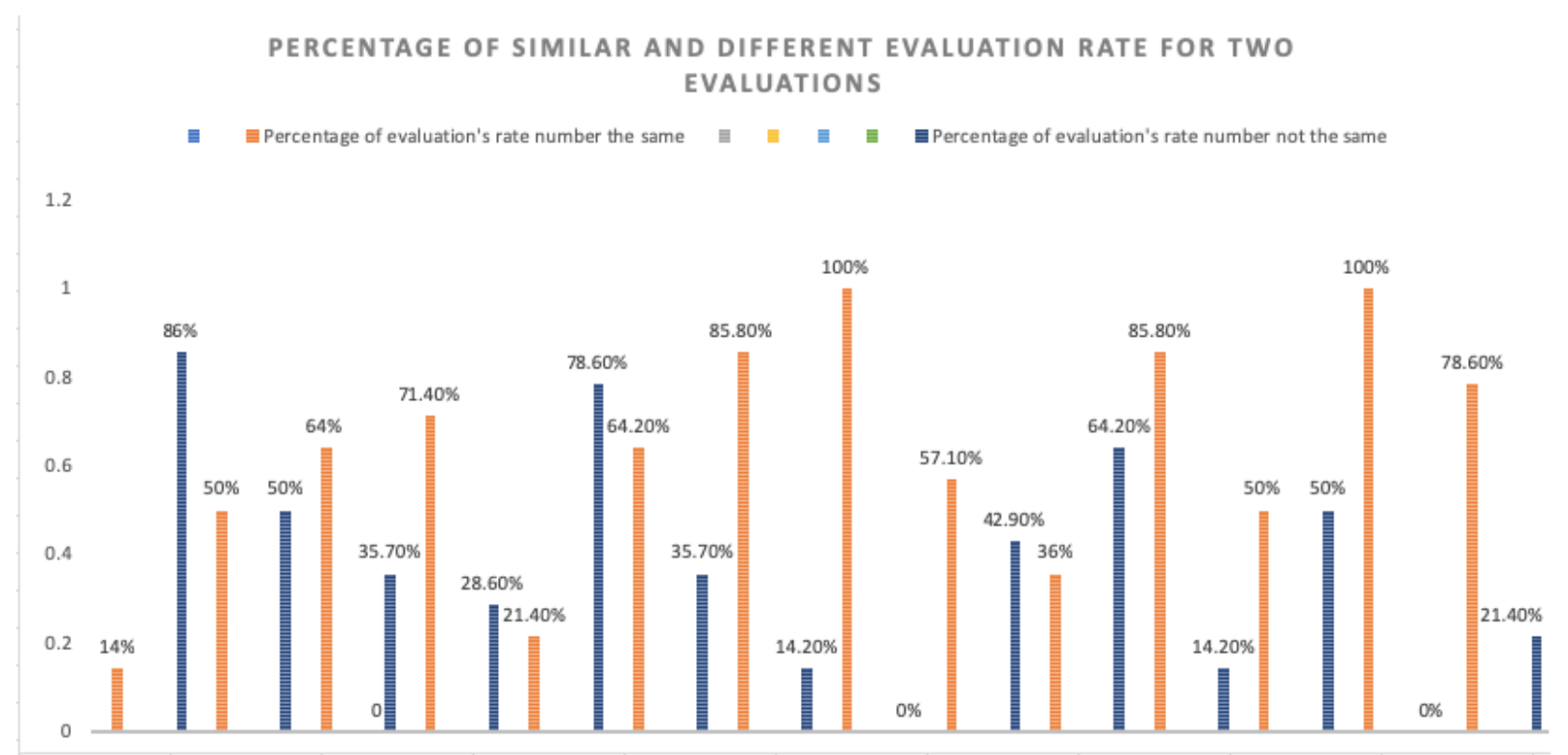

Figure 1: The percentage of similar and different evaluation rate for two evaluations

The survey questions are mainly about three fields, which are feeling of themselves, emotional response under certain situations, and interpersonal interactions. The participants first finished a survey of evaluation on their role model. After finishing the evaluation for their role model, participants will do the same survey test again, but this time they evaluate themselves. Question one to question five were questions focusing on the participant's feeling of themselves. Those questions asked the participants whether they consider themselves as successful or not, or are you likable to others. Question six to ten asked questions about the participant's evaluation toward their interpersonal interactions in daily life. Participants were asked to rate their social skills and what others people think of them. Questions like whether people think you're boring to talk to, and whether I will be discouraged if others told me that I'm not doing my best. Question eleven to question fourteen asked questions about the emotional response when the participant was under a specific situation. The result of the survey will be categorized into three fields, and the comparison of the two evaluation will be separated. The categorized result will show in which field does the participants evaluate themselves similar to their role model.

\subsection{Sample:}

With in the survey study, the participants were selected from a middle school. Sampling method like random sampling was not applied, because the overall sample base was relatively small. Participants were 32 undergraduate middle school students enrolled from different grades either ninth, tenth, or eleventh grade. Those participants participated the study voluntarily. The age range was from 15 to 18 years old. Within the sample, there were 17 female participants and 13 male participants, which gives approximately the percentage of $56.6 \%$ of the sample were females and $43.4 \%$ were males.

\subsection{Procedure:}

The study began by a short and brief explanation of the study, including the goal of the study and what participants need to do to complete the study. After the short introduction, participants will be doing the survey about their evaluation about their role model first; after completing the first survey, participants will start the second survey, which is the evaluation about themselves. When participants finished both of the survey, they will receive a small reward. After all the participants finished both of surveys, all the surveys were carefully verified in case there's any invalid results collected. The survey usually took 10 to 15 minutes to complete.

The next step of the study was to compare each of the participant's evaluation to their role model and their own self-evaluation. The comparation's goal is to see is there any consistency between the participant's self-evaluation and their role model.

\subsection{Measure:}

The study will examine the rate number the participant gave on their role model test and the rate number they gave for themselves. When there is over $50 \%$ of consistency between rate numbers for questions in the survey, the results between the survey for role model and the self-evaluation survey will be consider as similar. A larger percentage of consistency means that the participant considers themselves more alike with their role model. 


\subsection{Result:}

The study successfully collected 30 qualified results, the other two was disqualified because of the untruthfulness. Both of the two disqualified results has ratings that was not credible and usable since they both of the results choose were made up by rate number of 1 . It was hypothesized that the rate number for the evaluation of the participants' role model and their actual self-evaluation will be similar. From the result of fourteen questions, there were nine questions with the percentage greater or equal to $50 \%$ of participants who rate themselves similar as their role model. As we can see from the results, there's a clear data trend in the percentage. Students tend to evaluate themselves similar to their role models for question 6-10 and 11-14. For the group of question 6-10, except question 10, all the other questions had a greater or equal to $50 \%$ percent similar ratings. As from the result from the group of question 610 , participants evaluate themselves more similar toward their role model in interpersonal interactions and social skills. Question 11-14 focused on the emotion response of the participants under hypothetical situations. All the questions had a greater or equal to $50 \%$ of similar ratings. We can see from the data that the majority of participants consider themselves having similar response when they are under the same situation with their role model. Participants tend to consider themselves similar with their role model in interpersonal interaction and emotion response. However, for the first five questions focusing on self-awareness, the ratings varied a lot. The mean rating number of the evaluation of role model and selfevaluation for question 6-10 and question 11-14 is quite close, but the mean number for question 1-5 varied significantly. Participants tend to rate themselves lower than their role model when it comes to self-awareness. Therefore, we can conclude from the result of the study that participants tend to evaluate themselves similar to their role model or ideal self in interpersonal interactions and emotional response. For the reason behind the tendency, through conjectures, we deducted that it was because interpersonal interactions and emotional response for the participants' role model are hard to know for those participants, so sometimes they make possible predictions. There predictions were mostly base on themselves, therefore their self-evaluations will be similar to their evaluations for their role models.

\section{GENERAL DISCUSSION}

Previous work has shown that others did affect our self-esteem and self-evaluation (Morse \& Gergen 1970) [18]. The aim of this study is to show that our substantial representation of ideal self may affect our own selfevaluation. Our own evaluation on questions and situations can be highly consistent with our evaluation toward our realistic ideal self. The study indicates that the substantial representation of participants' ideal self, or role model, will affect the self-evaluation of the subjects and make their self-evaluation closer to them.

The result of the study leads to further questions, because social comparison can happen from multiple aspects. An individual's self-evaluation can fluctuate and affect by not only the ideal self, other studies also indicates that changes in an individual's self can cause by shifts in their feelings under different situations (Lievens, Lang, De Fruyt, Corstjens, Van de Vijver \& Bledow 2018) [19]. Other individuals' presence can affect one's selfevaluations (Buckingham \& Alicke) [20]. Indeed, the substantially representation of our ideal self can have a smaller impact on individual's self-evaluation since we can have multiple role models in different fields, and role models can be successful or not honorable. Yet, it is still too early to say that role models really affected or selfevaluations, because the result of the study can't be generalized and results from time to time may vary. For future studies, the aim will be on finding ways to help individuals make proper and objective self-evaluations. As we know from the result of the study, social comparison can lead individuals to make evaluations similar to their role model. For further research, the study will be more focusing on how to eliminate the effect of social comparison and environmental factors or even competitiveness, so that the result of the self-evaluation can fit better with the individual's true self.

There are several limitations for this study that causes the result of the study not generalizable. The database for this study is relatively small, the sample base was limited to only a single middle school. Sampling method cannot be applied to the study, since the sample size was too small. Therefore, my sample cannot represent the whole population. Moreover, the test hasn't run through the test and retest process, which is a way to ensure the validity of the test. We can't make sure the result of the test will be similar and standardized, so the validity of the test is still questionable. The other limitation is about the evaluation itself. As in the study, we can see participants evaluate themselves similar to their role model when there were rating themselves on emotional response and interpersonal communication, so we can't tell whether the participant really think he or she was similar to their role model or they just think they'll do the same way as their role model does under certain situations. For this study, we can only analyze the trend, but for the influence of role models on the evaluation of a specific individual, it will not be very effective.

The significance of the study is in two ways. First, the study showed that individual's self-evaluation can be similar to their ideal self, which means that sometimes people's evaluation for themselves can be very idealized and biased. People can't always behave like their ideal self, however, when they're doing self-evaluation, they tend to rate themselves better as it supposed to be. By showing people that their evaluations are sometimes bias 
and idealized, it can help individuals to better establish a well-rounded self-concept. Occasionally, people overestimate their capability. But, when they failed, the attribution of the reason of the defeat will be on other factors except themselves (Kelley \& Michela) [21]. When individuals realized that sometimes they mistakenly estimate their true capabilities, they can establish a clearer self-concept. Social comparison can cause assimilation among people's self-evaluations (Rüter \& Epstude 2004) [22]. People's self-evaluation tends to be more and more similar due to the constant comparison with other people. By letting people know how their capabilities really are, people can at least have an overview of what they can do and avoid assimilations in some degree.

\section{CONCLUSION}

This research takes a step forward in understanding the influence of social comparison on self-evaluations when people use social media regularly. The result of this research shows that the self-evaluation of the participants themselves and the evaluation they do for their role models of are quite similar. However, due sampling limitations, the study result can't be generalized. In the future, studies should be carried out with a bigger sample space that can represent the whole population.

\section{REFERENCES}

[1] Gecas, Viktor. 1982. "The Self-Concept." Annual Review of Sociology 8:1-33.

[2] Rosenberg, Morris. 1990."The Self-Concept: Social Product and Social Force."Social Psychology: Sociological Perspectives, edited by Morris Rosenberg and Ralph H. Turner. Transaction, 593624.

[3] Gecas, V., \& Schwalbe, M. (1983). Beyond the Looking-Glass Self: Social Structure and EfficacyBased Self-Esteem. Social Psychology Quarterly, 46(2), 77-88.

[4] Sedikides, C., \& Strube, M. J. (1997). Self evaluation: To thine own self be good, to thine own self be sure, to thine own self be true, and to thine own self be better. In M. P. Zanna (Ed.), Advances in experimental social psychology, Vol. 29, 209-269.

[5] Farnham, D. S., Greenwald, G. A., \& Banaji, M. N. (1999). Implicit selfesteem. In D. Abrams \& M. Hogg(Eds.), Social identity and social cognition, 230-248

[6] John A. Bargh, Shelly Chaiken, Paula Raymond, Charles Hymes. (1996). The Automatic Evaluation Effect: Unconditional Automatic Attitude Activation with a Pronunciation Task. Journal of
Experimental Social Psychology, Volume 32, Issue $1,104-128$

[7] Fazio, R. H., Sanbonmatsu, D. M., Powell, M. C , \& Kardes, F. R. (1986). On the automatic evaluation. of attitudes. Journal of Personality and Social Psychology, 229-238.

[8] Murphy, S. T., \& Zajonc, R. B. (1993). Affect, cognition, and awareness: Affective priming with optimal. and suboptimal stimulus exposures. Journal of Personality and Social Psychology, 64(5), 723 739.

[9] Paulhus, D. L. (1993). Bypassing the will: The automatization of affirmations. In D. M. Wegner \& J. W. Pennebaker (Eds.), Handbook of mental control, 573-587.

[10] Sheldon Solomon, Jeff Greenberg, Tom Pyszczynski. (1993). A Terror Management Theory of Social Behavior: The Psychological Functions of Self-Esteem and Cultural Worldviews, Editor(s): Mark P. Zanna, Advances in Experimental Social Psychology, Academic Press, Volume 24, 93-159.

[11] Baumeister, R. F. (2010). The self. In R. F. Baumeister \& E. J. Finkel (Eds.), Advanced social psychology: The state of the science, 139-175.

[12] Boyatzis, R.E. and Akrivou, K. (2006), "The ideal self as the driver of intentional change", Journal of. Management Development, Vol. 25 No. 7, 624-642

[13] Festinger, Leon (1954), “A Theory of Social Comparison Processes," Human Relations, 7 (2), $117-40$.

[14] Chris L. Kleinke and William F. Miller. (1998). How Comparing Onself Favorably with Others Relates to Well-Being. Journal of Personality and Social Psychology P107-123.

[15] Wood, J. V. (1989). Theory and research concerning social comparisons of personal attributes. Psychological Bulletin, 106(2), 231-248

[16] Hui-Tzu Grace Chou and Nicholas Edge. (2012). "They Are Happier and Having Better Lives than I Am": The Impact of Using Facebook on Perceptions of Others' Lives. Cyberpsychology, Behavior, and social networking Vol 15, NO.2

[17] Jones, E.E., \& Gerard, H. (1967). Foundations of social psychology. Wiley

[18] Morse, S., \& Gergen, K. J. (1970). Social comparison, self-consistency, and the concept of self. Journal of Personality and Social Psychology, 16(1), $148-156$. 
[19] Lievens, F., Lang, J. W. B., De Fruyt, F., Corstjens, J., Van de Vijver, M., \& Bledow, R. (2018). The. predictive power of people's intraindividual variability across situations: Implementing whole trait theory in assessment. Journal of Applied Psychology, 103(7), 753-771.

[20] Buckingham, J. T., \& Alicke, M. D. (2002). The influence of individual versus aggregate social comparison and the presence of others on selfevaluations. Journal of Personality and Social Psychology, 83(5), 1117-1130.

[21] Harold H. Kelley and John L. Michela. (1980) Attribution theory and research. Annual Review of Psychology 1980 31:1, 457-501

[22] Mussweiler, T., Rüter, K., \& Epstude, K. (2004). The Ups and Downs of Social Comparison: Mechanisms of Assimilation and Contrast. Journal of Personality and Social Psychology, 87(6), 832-844 